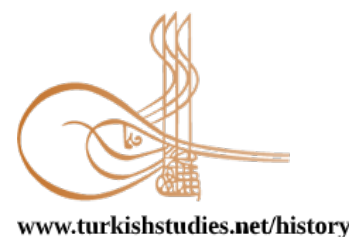

Turkish Studies - Historical Analysis

eISSN: 2667-5552

Research Article / Araștırma Makalesi

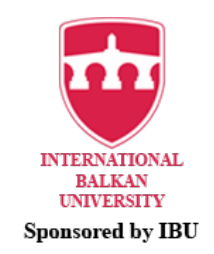

\title{
Doğumunun 140.Yılında Neyzen Tevfik (Büyük Taarruz’a Bakışı ve Çeşitli Yönleriyle)
}

Neyzen Tevfik in the 140th Year of Birth (Looking at the Big Attack and His Various Aspects)

\author{
Selman Yaşar
}

\begin{abstract}
Neyzen Tevfik who is a musician and poet throughout his life, he gained fame with playing Ney, and later produced satirical works. He also wrote poems about the National Struggle and the Great Offensive. In addition, he has many compositions. He has been among the most sought-after artists with his mastery in playing ney. Neyzen Tevfik could not lead a regular life besides his artistic personality. Due to temperament money, authority, goods, property and so on. He did not care about anything. Throughout his life, he did not want any of these, although all doors were opened to the end. The works he gave during his life and the events he experienced were spread from language to language and recognized by the public. As a result, the name Neyzen Tevfik has been in the memory of theTurkish nation. Neyzen Tevfik, who was born in Bodrum due to his father's office, is one of the leading artists of Turkish literatüre and art. He is both a poet who wrote poetry and a musician playing ney. In his life time, his reputation for playing ney alongwith his poems spread all over the country. He established a throne in the hearts of theTurkish people with his life and works. He suffered various ailments during his life time and remained in a mental hospital for a while due to health problems. He could not lead a regular life dueto his addiction todrinking. He was left without money, lay on the streets, and was swept up and down. He was loved by everyone with his poetry and mastery of playing ney, although he criticized many in his poems, the number of people around him did not decrease. Since he did not care about money, he was left without money, and although he was given many helpfrom his environment, he distributed the money he had, the clothes on it to those around him and those in need. Neyzen Tevfik, who played in the presence of Atatürk and witnessed the National Struggle and the Great Offensive, also wrote poetry about Atatürk and the Great Offensive. Neyzen, who has a fine spirit besides his poetry, loved the animals and even organized a funeral for one of them. Neyzen Tevfik, who did not accept any of them despite the allocation of houses and mansions, lived on the streets, slept in mosque courtyards, coffee houses, encountered many people and many events throughout his life, and his love for the people increased with his life and works. Neyzen Tevfik, who has an important place in Turkish literatüre and art with his poems, wit and mastery, has still not been forgotten, but his Works and witnesses have spread from language to language.
\end{abstract}

Structured Abstract: Introduction and Purpose of the Study:

Neyzen Tevfik was born in Bodrum on June 14, 1879. He was interested in poetry from a young age and met ney for the first time in Bodrum in those years. Ney voice deeply influenced Tevfik. After that, he made an effort to learn and play. Neyzen, who got sick for a while, had a seizure in 1893 and was later taken

\footnotetext{
* Doç. Dr., Batman Üniversitesi Fen-Edebiyat Fakültesi Tarih Böümü. Associate Professor, Batman University, Faculty of Arts and Sciences, Department of History. ORCID 0000-0002-1396-295X

selman.yasar@batman.edu.tr

Cite as/ Atıf: Yaşar, S. (2020). Doğumunun 140. yılında Neyzen Tevfik (Büyük Taarruz'a bakış1 ve çeşitli yönleriyle). Turkish Studies - History, 15(2), 711-722. https://dx.doi.org/10.29228/TurkishStudies.40499

Received/Geliş: 10 January/Ocak 2020

Accepted/Kabul: 20 June/Haziran 2020

Checked by plagiarism software

Copyright $(\mathrm{C}$ INTAC LTD, Turkey

Published/Yayın: 25 June/Haziran 2020

CC BY-NC 4.0
} 
to Istanbul for treatment. A doctor here recommended that he be released and allowed to act as he intended. Neyzen Tevfik, who stopped his education due to his discomfort, started writing poetry, playing ney and mastered ney stealing and satire over time. His first poem was published in the magazine Muktebes in Izmir on April 30, 1898. He attended the lessons of Neyzenbaşı Cemal Bey in İzmir Mevlevihanesi and improved the playing of ney. During these lessons, he also learned the knowledge of notes, and he blew ney at the whirling ceremonies organized by meeting the art scene of İzmir. Neyzen Tevfik, who came to Istanbul later, acquired an environment thanks to Akif after meeting Mehmet Akif and started to blow ney and increase his reputation in the invitations there. Neyzen took lessons from Mehmet Akif and improved his talent in poetry. In 1918, poetry books titled "Kaç" and "Azab-1 Mukaddes" were published in 1949. Having stayed with his brother Şefik Bey in Ankara for a few months after the establishment of the Republic on 29 October 1923, Neyzen later went to Bolu and published other poems with his poem "Karakaytaz" in the newspaper "Dertli". In 1926, in the trip of Atatürk in Balıkesir, what played in the presence of Him. Neyzen, who gained the appreciation of Atatürk, also explained the National Struggle in his poems. Neyzen Tevfik also wrote a poem called 26 August Offensive on the anniversary of the Great Offensive and the Commander-in-Chief Victory with the effect of the Commander-in-Chief Victory won under the leadership of Atatürk.

\section{Conceptual / theoretical framework on the subject of study:}

Neyzen Tevfik, who was born in Bodrum due to his father's office, is one of the leading artists of Turkish literatüre and art. He is both a poet who wrote poetry and a musician playing ney. In his life time, his reputation for playing ney alongwith his poems spread all over the country. He established a throne in the hearts of theTurkish people with his life and works. He suffered various ailments during his life time and remained in a mental hospital for a while due to health problems. He could not lead a regular life dueto his addiction todrinking. He was left without money, lay on the streets, and was swept up and down. He was loved by everyone with his poetry and mastery of playing ney, although he criticized many in his poems, the number of people around him did not decrease. Since he did not care about money, he was left without money, and although he was given many helpfrom his environment, he distributed the money he had, the clothes on it to those around him and those in need.

\section{Method:}

The related literature has been scanned. In accordance with the science of history, the subject was examined, syntheses and analyzes were done on the subject. As a result, the subject has been handled from different perspectives depending on the findings that have been handled in various aspects.

Findings and Discussion:

Neyzen Tevfik, who played in the presence of Atatürk and witnessed the National Struggle and the Great Offensive, also wrote poetry about Atatürk and the Great Offensive. Neyzen, who has a fine spirit besides his poetry, loved the animals and even organized a funeral for one of them. Neyzen Tevfik, who did not accept any of them despite the allocation of houses and mansions, lived on the streets, slept in mosque courtyards, coffee houses, encountered many people and many events throughout his life, and his love for the people increased with his life and works. Neyzen Tevfik, who has an important place in Turkish literatüre and art with his poems, wit and mastery, has still not been forgotten, but his Works and witnesses have spread from language to language.

\section{Conclusion and Suggestions:}

As a result; Neyzen Tevfik, a great satire and ney master, was brought up free by his family after his illness as a child. In this process, Neyzen, who started playing ney in Bodrum, started to write poems after meeting Mehmet Akif. Besides Akif, he wrote poems under the influence of poet Eşref. He gained a reputation for what he mostly became, and later became a sought-after artist of the country. Tevfik, who also has compositions besides many of his poems, advanced in satire and satirized everyone. Despite this, nobody was angry with Him, but they were more than pleased with His satire. They tried to lead a comfortable life due to his artist personality, but Neyzen Tevfik pushed them with the back of his temperament. Although he was allocated houses, salaries, and was fed and drunk throughout his life, he could not get used to this comfortable life and returned to the streets and slept in the streets. During this life, Neyzen encountered many interesting events and people, and many of these events took place. During this period, these interesting events spread among the people and the love of the people for him increased. In addition to his nigthiness, he gained an unforgettable place in the hearts of the Turkish nation with his wit. 
Keywords: Neyzen Tevfik, History, NationalStruggle, Big Attack, Ney, Satire.

Öz: Müzisyen ve şair olan Neyzen Tevfik yaşamı boyunca Ney çalması ile ün kazanmış, sonrasında hiciv alanında eserler vermiştir. Milli Mücadele ve Büyük Taarruz'la ilgili şiirler de yazmıştır. Bunların yanısıra birçok bestesi de vardır. Özellikle ney çalmadaki ustalı̆̆ı ile döneminin aranılan sanatçıları arasında yer almıştır. Neyzen Tevfik, sanatçı kişiliğinin yanında düzenli bir yaşam sürdürememiştir. Mizacı nedeniyle para, makam, mal, mülk vb. hiçbir şeye önem vermemiştir. Hayatı boyunca kendisine bütün kapılar sonuna kadar açılmasına rağmen bunların hiçbirini istememiştir. Yaşamı süresince verdiği eserler, yaşadığı olaylar dilden dile yayılmıș ve halk tarafından tanınmıştır. Bunun sonucunda Neyzen Tevfik ismi Türk milletinin hafızasında yer etmiştir. Babasının memuriyeti dolayısıyla Bodrum'da doğan Neyzen Tevfik, Türk edebiyat ve sanatının önde gelen sanatçılarından biridir. Hem şiir yazan bir şair hem de ney çalan bir müzisyendir. Yaşadığı dönemde, şiirlerinin yanısıra ney çalmadaki ünü tüm ülkeye yayılmıştır. Yaşamı ve verdiği eserleriyle Türk halkının gönlünde taht kurmuştur. Yaşadığı dönem boyunca çeşitli rahatsızlıklar geçirmiş, sağlık problemleri nedeniyle bir süre akıl hastanesinde dahi kalmıştır. İçkiye bağımlılı̆̆ı nedeniyle düzenli bir hayat sürememiştir. Parasız kalmış, sokaklarda yatmış, bir oraya bir buraya savrulmuştur. Şiirleri ve ney çalmadaki ustalığı ile herkes tarafından sevilmiş, şiirlerinde birçok kişiyi eleştirmesine rağmen çevresindeki insanların sayısı azalmamıştır. Paraya önem vermediğinden dolayı parasız kalmış, kendisine çevresinden birçok yardım yapılmasına rağmen elindeki paraları, üzerindeki giysileri çevresindekilere, ihtiyaç sahiplerine dağıtmıştır. Atatürk'ün huzurunda ney çalan, Milli Mücadele’ye ve Büyük Taarruza yakından şahit olan Neyzen Tevfik, Atatürk ve Büyük Taarruz ile ilgili de şiir yazmıştır. Şairliğinin yanısıra ince bir ruha sahip olan Neyzen, hayvanları çok sevmiş, hatta bunlardan biri için bir cenaze töreni bile düzenlemiştir. Kendisine evler, konaklar tahsis edilmesine rağmen bunların hiçbirini kabul etmeyen Neyzen Tevfik, sokaklarda yaşamış, cami avlularında, kahvehanelerde yatmış, yaşamı boyunca birçok kişiyle ve birçok olayla karşılaşmış, yaşamı ve eserleriyle halkın kendisine olan sevgisi artmıştır. Şiirleri, nükteleri ve ney çalmadaki ustalığı ile Türk edebiyatı ve sanatında önemli bir yeri olan Neyzen Tevfik, aradan bunca zaman geçmesine rağmen hala unutulmamış, eserleri ve nükteleri dilden dile yayılmıştır.

Anahtar Kelimeler: Neyzen Tevfik, Tarih, Milli Mücadele, Büyük Taarruz, Ney, Hiciv.

Neyzen Tevfik, 14 Haziran 1879 tarihinde Bodrum'da dünyaya gelmiştir. Küçük yaşlardan itibaren şiire ilgi duymuş(Yaşar, Haziran 2010:1947), o y1llarda Bodrum'da ilk kez ney ile tanışmıştır. Ney sesi Tevfik'i derinden etkilemiştir. Bundan sonra ney öğrenmek ve çalmak için çaba harcamıştır (Yaşar, Aralık 2016:34). Bir ara hastalanan Neyzen, 1893 y1lında bir sara nöbeti geçirmiş, daha sonra tedavi için İstanbul'a götürülmüştür. Buradaki bir doktor, kendisinin serbest bırakılması ve istediği gibi davranmasına müsaade edilmesini tavsiye etmiştir. Rahatsızlığı sebebiyle eğitimini yarım bırakan Neyzen Tevfik şiir yazmaya, ney çalmaya başlamış ve zamanla ney çalma ve hicivde ustalaşmıştır. İlk şiiri 30 Nisan 1898'de İzmir'de Muktebes adlı dergide yayınlanmıştır. İzmir Mevlevihanesi'ndeNeyzenbaşı Cemal Bey'in derslerine katılarak ney çalmayı geliştirmiştir. Bu dersleri sırasında nota bilgisini de öğrenmiş, İzmir'in sanat çevresi ile tanışarak düzenlenen sema törenlerinde ney üflemiştir.

Daha sonra İstanbul'a gelen Neyzen Tevfik, Mehmet Akif'le tanıştıktan sonra Akif'in sayesinde çevre edinmiş ve buradaki davetlerde ney üflemeye ve ününü arttırmaya başlamıştır (Yaşar, Haziran 2010:1947,1948). Neyzen, Mehmet Akif'ten ders almış ve şiirdeki kabiliyetini geliştirmiştir (Karaalioğlu, 1983:556). 1918 yılında Hiç ve 1949 yılında Azab-1 Mukaddes adlı şiir kitapları yayımlanmıştır (Mutluay, 1973:115,239).

29 Ekim 1923'te Cumhuriyet kurulduktan sonra birkaç ay Ankara'da kardeşi Şefik Bey'le beraber kalan Neyzen, daha sonra Bolu'ya giderek buradaki "Dertli" gazetesinde "Karakaytaz" mahlasıyla "Türk'ün Destânı" adlı şiiriyle beraber başka şiirleri de yayımlamıştır. 1926 yılında (Usta, 1985:31,32) Atatürk'ün Balıkesir gezisinde O'nun huzurunda ney çalmıştır. Atatürk'ün de beğenisini kazanan Neyzen (Kabacalı, Kasım 2003:32), Milli Mücadeleyi şu dizeleriyle anlatmıştır: 
Bir belâsın itilâfın kuvveti mağruruna

Bir kırık kağniyle çıktın fenni harbin turuna (Hakkı Süha, 29 Birincikânun 1939:5).

Neyzen Tevfik, Atatürk'ün önderliğinde kazanılan Başkomutanlık Zaferi'nin etkisiyle, Büyük Taarruz ve Başkomutanlık Zaferi’nin yıldönümünde 26 Ağustos Taarruzu adlı bir şiir de yazmıştır. Tevfik, bu şiirinde, Büyük Taarruz'u kendine özgü üslubuyla, şu şekilde anlatmıştır (Usta, 1985:214-216):

\section{Ağustos Taarruzu}

Gönlüm yine derinde

Ankara güllerinde

Kara sevda sizliyor

Sazımın tellerinde

Ay yıldızlı bayrăğım

Senin altında sağım

Kara kalpak yan durur

Daha mı düşman durur

Çiğnediğim yerlerde

Şanlı bir Tûran durur

Ay yıldızlı bayrăğım

Senin altında sağım

Paşam düşman göründü

Cepheler bize döndü

Emir ver yürüyelim

Vatan kara büründü

Ay yıldızlı bayrağım

Senin altında sağım

Başkumandan çok yaşa

Mustafa Kemal Paşa

Destanların yazıldı

Basdığın dağa taşa

Ay yıldızlı bayră̆ım

Senin altında sağım

Ağustos yirmi altı

Akşam çöktü karaltı

Hazırlandı düşmana

$\mathrm{Bu}$ gece yerin altı

Ay yıldızlı bayră̆ım

Senin altında sağım

Tan yıldızı batıyor

Fecir aydınlanıyor 
Düşümde yâri gördüm

Beni şehit sanıyor

Ay yıldızlı bayrağım

Senin altında sağım

Tutmam ölüm yasını

Yar çeksin tasasını

Kocatepe'de kurduk

Tarassut noktasinı

Ay yıldızlı bayrağım

Senin altında sağım

Gönlümüz firsat arar

Ordumuz tuttu karar

Akar çayın üstünden

Dumlupinar'a kadar

Ay yıldızlı bayrağım

Senin altında sağım

Bülbül ne var sesinde

Bir yâr sevdim Mersin'de

Yürü emri okunmuş

Ankara meclisinde

Ay yıldızlı bayrağım

Senin altında sağım

Vatan benim yâr benim

Gönlüm yine dar benim

Vurulursa sevdiğim

Gel yaramı sar benim

Bayrağımın yıldızı

Saramadım o kızı

Ankara'dan yar gelir

Al bayrak uçar gelir

Y1ldırım orduları

Ateşler saçar gelir

Bayrağımın yıldızı

Saramadım o kızı

Tel örgüyü ben geçtim

Akar çaydan su içtim

Beşbin atlı içinde

Seni uzaktan seçtim 
Bayrağımın yıldızı

Saramadım o kızı

Tel örgüyü aştılar

Afyon'a yaklaştılar

Tinaztepe tutuldu

Görenler hep şaştılar

Bayrağımın yıldızı

Saramadım o kızı

26 Ağustos 1923

Ankara-Etlik

Herkes tarafından sevilen Neyzen Tevfik, para, pula, rahat yaşama önem vermiyordu. $\mathrm{Bu}$ nedenle birçok kişi kendisine konaklarını evlerini tahsis ettiği halde $\mathrm{O}$, bu rahat yaşamı becerememiş, sokaklarda yaşamış, geceleri kaldırımlarda yatmıştır. Rahatsızlandığı zaman da Bakırköy Akıl Hastalıkları Hastanesi'nde ve Haydarpaşa ile Cerrahpaşa hastanelerinde belirli bir süre kalmıştır. Bunların dişında kardeşi olan Şefik Bey'in Pendik semtindeki evinde kalmıştır. Yaşamının son yıllarında kendisine Nuri Demirağ tarafından verilen ahşap bir evde yaşamıştır. $\mathrm{Bu}$ dönemde kendisine 50 lira aylık da tahsis edilmiştir. 1953 yılında rahatsılanmış, müzmin bronşit hastalığ nedeniyle 3 ay hasta yatmış ve 28 Ocak 1953 'te vefat etmiştir (Yaşar, Haziran 2010:1952).

Neyzen Tevfik, ömrünün sonlarında içlerinde siroz hastalığının da bulunduğu birçok hastalığa yakalanmıştı. Mesleğindeki son jübilesinin yapıldığı zaman halsiz ve bitkin durumdaydı (FirdevsiîTûsiGandhi Neyzen Tevfik Ahmet Cevdet Paşa, 1959:37-51). Vefatından bir ay önce felç geçirmişti. Bu rahatsızlı̆̆ nedeniyle son günlerinde az konuşmuştu. Çevresindekilerin hastanede tedavi olmasını istemelerine rağmen bunu kabul etmemişti. Bunun sebebini soranlara da şöyle demişti: "Bu sefer öleceğimi bildiğim için gayretler nafile... Hem şimdiye kadar takriben 15 ton rakı içtim. Bir insan bedeninin bunu nasıl kaldırdığına doktorlar akıl erdiremiyorlar. Hastanede ölürsem, muhakkak otopsi yaparak sebebini keşfetmek isterler..." ("Neyzen Tevfik' in Son Seneleri ve Son Hatıraları...", 13 Şubat 1953:8). Doktor Neşet Halit de Neyzen'in içki içmesiyle ilgili olarak şunları söylemiştir: "Ne rakl, ne de şarap Neyzen'in vücudunda en küçük bir tesir yapamamıştır. Bir vazelin gibi girmiş ve çıkmıştır" (Alpman, 1972:59).

Doktor Rahmi Duman da bu konuyla ilgili olarak Neyzenin içkiyi biberon gibi içtiğini ve içerken kendini kaybettiğini, uzun zamanlar ara verse bile tekrar içkiye başladığını belirtmiştir. Hatta bir gece komaya girdiğini, iki gün sonra kendine geldiğini, kendinde olmadığ i için gözünü bir yere çarptığını, gözünün şişmiş haliyle çektiği fotoğrafı kendisine gösterdiğinde, Neyzen'in fotoğrafin arkasına beş-on tek attığını, çağın kötülüklerini görmemek amacıyla bir gözünü kapattığını yazdığını söylemiştir(Tarı, 26 Ocak 1973: 11).

Mehmet Akif, Neyzen'in bu durumuna çok üzülüyordu. O'nun içkiden uzak durması için çok gayret etmişti. Neyzen de Akif'i sevdiğinden dolayı her defasında içki içmeyeceğine dair yemin etmekteydi. Fakat Neyzen, yine de bu sözlerinin hiçbirini tutma başarısını gösterememiştir. Buna rağmen Akif, Neyzen'e karşı hep 1lımlı yaklaşmıştır (Yaşar, 19-22 Kasım 2008:723). Akif, Neyzen'in kendisine defalarca söz vermesine rağmen tekrar içkiye başlamasıyla ilgili olarak Safahat'inda bulunan, Neyzen Tevfiğinüçbindörtyüzüncü tövbesinden istifası münasebetiyle "DervişAhmed" adlı bir şiir yazmıştır(Ersoy, 1999:521-523). Neyzen Tevfik de bu yönüyle ilgili olarak anılarında, yıllarca içki içtiğini, bir gün babasının kendisini tuz almak için bakkala gönderdiğini, ancak birbuçuk yıl sonra ancak eve dönebildiğini, aylarca yemek yemediğini, parasız kaldığında sadrazam Talat Paşa'dan para aldığını, parası olsa da sokaklarda, Yenicami'nin arkasında, Arnavut İsa'nın kahvesinde, bazen köpeklerle koyun koyuna yattığını, akıl hastanesinde 
de kaldığını, bu yüzden doktor Mazhar Osman'la arasının iyi olduğunu, çevresinde her türlü insan olduğunu, onların kendisine baktığını, kendisinin de onlara sadece ney çaldığını söylemiştir (Münir Süleyman, 13 Eylül 1953:4,5).

Yüksel Baştunç anılarında Neyzen'le ilgili olarak şunları anlatmıştır: "Bakırköy Akıl Hastanesi'ni Mazhar Osman'dan teslim alan, sonradan İstanbul'un mini mini valisi Fahrettin Kerim Gökay'dan müsaadeliydi...Belki acele lazım olur diye lastik kapaklı küçük şişelerde hazır tutulurdu. Derken kartviziti gelirdi. Bu iki karış boyunda sert bir ağaçtan yontulmuş her zaman beyaz olan bir değnekti. Kendi gelmediği zamanlar bu değnek kartviziti yollayarak ilacını alırdı. Nedense Neyzen'in yanında hep kafadan sakat çömezleri olurdu. Bunlar ya köse ya cüce veya dilsiz gibiydiler. Çömez getirir değneği veznenin üzerine koyar, hiç konuşmadan beklerdi...Illacı itina ile iç cebine yerleştirirdi. Dışarı çıkınca sanki kendini takip eden olup olmadı̆̆ına emin olduktan sonra değnek elinde tazı gibi uzaklaşırdl..."

Bazen de ilacını almaya kendisi gelirdi. "Yarı açılmış kapıdan başını uzatır seslenirdi:

-Merkebi yıkamaya götürüyorum Hakkı, çulu kalmadı, çul ister.

-Çıkarken hazır olur, sen çömezi yolla.

-Merkep minnettar kalacaktır.

Bu konuşmalar olurken ben eşeği hamamına alacak bir hamamcının olup olmayacă̆ını düşünürdüm. Birkaç saat sonra yine kapıda görünürdü...Temiz pak. Kalın dudaklarını büzerek konuşuyor:

-Merkebi yıkadık.

-Sihhatler olsun. Güle güle kirlen.

Önceleri arkasında temiz pak olmuş bir eşek arardım hep. Sonunda merkebin kendisi olduğunu anladım. Neyzen hava almak istediğinde merkebi gezdirir, içki içerken merkebi sular, uyuşturucu canı çektiğinde merkep harmandır..." (Baştunç, 1991:8-25).

Birçok kez içkiyi bırakan Tevfik, bir dönem beş altı ay içkisiz durabilmiş, bu sürede bir kütüphanede kitap okumuştur. Biraz hava almak için kısa bir süreliğine evden çıkmış, daha sonra tekrar içkili bir şekilde evine dönmüş̧ür. Üsküdar'da Şemsipaşa medresesinde kaldığ 1 dört ay boyunca da içkiye el sürmemiştir. Bir ara yine gezmek amacıyla dışarı çıkan Tevfik, eve hem sarhoş hem de başı gözü yaralı bir şekilde dönmüştür(Çapanoğlu, 1942:32,33).

Yine içkiyi bıraktığı zamanların birinde içkinin yerini yemek sevgisi almıştı. Bunu da anılarında şöyle anlatmıştır: "Şimdi bende bir tek sevgi var. Yemek sevgisi...Bu sevgi bana sazı da, sözü de, şiiri de, musikiyi de unutturdu. Şöyle bol tereyağll bir pilâv, (Rafael)in tablolarını seyrederken duyduğum heyecan kadar, belki daha fazla bir zevk veriyor. Hele buzlu bir vişne hoşafindaki renk, bilmem hangi tablonun hangi renginde var. Ve bu güzel rengi hangi ressam tablosunda, hangi şair manzumesinde bu kadar muvaffakiyetle canlandırabilir. Hele bir kılıçbalı̆̆ının lezzetini, şairlerimizin manzumelerinde bulabilir misin, birindeki lezzet ile, öbüründeki burukluk ne kadar âşikârdır.

Ben üç sene var ki ağzıma bir katre rakı koymuyorum. Şimdi yegâne düşüncem yemek yemektir. Dostlartmdan kime rasgelsem, slhhatinden evvel bildiği güzel yemeklerin isimlerini ve nasıl pişirildiğini soruyorum. Bazı günler çok, haddinden fazla yediğim halde gene bir türlü doymuyorum. Mamafih, on beş günde bir midemde bir akademi toplantyor, bu akademi âzâları "bugün artık az yiyeceksin, bir yumurta, biraz yoğurt kâfi!" diyorlar, ben de az yiyorum. Şurasını $d a$ söyliyeyim $k i$, insanın iştihası olmak demek, muazzam bir çiftliği, milyonlarca treni var demektir. İspanya'nın Elhamra Sarayını bir yumurtaya değişmem" (Münir Süleyman, 13 Eylül 1953:5). 
Yüksel Baştunç ile arası iyi olan Neyzen, Baştunç'u ziyarete gittiğinde Baştunç'un annesi ona pirinç çorbası pişirirdi. Bu çorbayı çok seven Neyzen, en iyi çorbayı şöyle tarif ederdi: "Çorbanın maydonozu içinde pişmiş olacak. Üzerine bol limon sıkllacak. Höpürdetirken devamlı oh çekeceksin..." (Baştunç, 1991:29).

Neyzen Tevfik'i yakından tanıyan Nuri Engin, O'nun için makamın ve mevkinin hiçbir değeri olmadığını, çoğu kez meyhanelerde sabaha kadar durduğunu, yada kaldırımlarda sabahladığını belirterek; “Ben Neyzen Tevfiği İstanbul'da Tophane'deki çeşme yalaklarının içinde çok gördüm...Ney'i ve şişesi yanında, saçı sakalı birbirine karışmış bir halde idi" demiştir (Engin, Ocak-Şubat 1982:15). Neyzen Tevfik, içkiyi bırakması ve dinlenmesi için bazen hastaneye yatırılırdı. Bazı zamanlarda da kendisi çıkar gelirdi. Neyzen'in burada kendine ayrılmış özel bir odası vardı (Dino\&Güler, ty:22). 21 numaralı koğuş ona ayrılmıştı (İnce, 16 Mart 2007:4). Tevfik burada sanki bir imparatorlukta yaşıyordu. Çevresinde kendisini yakın hissettiği insanlar vardı ve bunların arasında mutlu bir hayat yaşamaktaydı (Berk\&Koloğlu, Ekim 1971:27). Hastalar üzerinde otoritesi vardı. Yanında emireri gibi duran bir kişiyi Muhittin Kutbay’a şöyle tanıtmıştı: "Meşhur Napolyon Bonapart! Fakat şimdi gönüllü olarak benim hizmetimde bulunuyor. Eksik olmasin. Sobamı yakar, çayımı pişirir, misafirlerimi karşılar" (Yücebaş, 1973:54,55). İçki içmeyi bırakmaya çalıştığında hastanede kendi tabiriyle "tımara ve kalafata" çekilirdi. "Onun kalafat yeri Haydarpaşa Cerrahpaşa hastaneleriydi. Son beş, on yıl içinde Bakırköy Hastanesi ...” (Çapanoğlu, 1942:34).

Burasını kendi evi olarak görürdü. Bir gün kendisini hastaneye kimin getirdiği sorulunca, buraya kendi isteğiyle geldiğini, burada haysiyetli insanların yaşadığı, evi olduğunu söylemiştir (Yücebaş, 1973:256).

Neyzen Tevfikanılarında, rahat ve huzurlu olsa, parası olsa böyle iyi ney çalıp şiir yazamayacağını, para biriktiremeyeceğini, kendisinin herkesten daha zengini olduğunu, İstanbul'da kimin evine gitse kendisini herkesin tanıdığını ve kendisine iyi baktıklarını, bankadan bile zengin olduğunu, zenginlik içinde yaşasa çoktan öleceğini söylemiştir. (Ergün, 1983:164,165). Yine bu anılarndan birinde, bir gün kendisinin bir konağa götürüldüğünü, yedirilip, giydirilip, içirilmesine rağmen dayanamayıp kaçtığını, kendisine verilen elbiseleri Galata'daki meyhanelerde yanındakilere verdiğini, kendisini bir makinist tulumu giydiğini Cebindeki paraları da çevresindekilere dağıttığını anlatmıştır (Münir Süleyman, 13 Eylül 1953:5).

Cahit Irgat Neyzen'in bu yönüyle ilgili bir hatırasında bir gün Neyzen'le karşılaştığını, çevresine fakir çocukları topladığnı, onlara çay ikram ettiğini, daha sonra hepsini Mahmutpaşa'ya götürüp onları giydirdiğini anlatmıştır (Yücebaş, 1973:260).

Paraya önem vermeyen Tevfik, Talât Paşa'dan aldığı paraların çoğunu yolda rastladığı dilenen kişilere dağıtıyordu (Çapanoğlu, 1942:29). Kendisini arada giydirirlerdi. Ancak o yine bir fırsatını bulup üzerindekileri çevresindekilere verirdi. Yine bir gün yeni elbiselerini ihtiyacı olan birine vermişti. Bir keresinde de jübilesi nedeniyle kendine verilen parayı eşinin ameliyatını yapamayan, işsiz, bu nedenle ağlayan bir kişiye vererek; nasıl olsa kendisine bir şekilde tekrar para vereceklerini söylemiştir (Özata, Eylül 1977:30). Başka bir gün de ayı oynatan birine yardım ederek ayı oynatmış ve bu kişinin para toplamasına yardımcı olmuştur (Yücebaş, 1955:268,269). Yüksel Baştunç'un anılarında anlattı̆̆ına göre, bir arefe günü Şehzadebaşı'ndaki esnaf Neyzen'i bir güzel giydirmişti. Yeni elbiseleriyle Fevziye Kıraathanesine giden Neyzen, fakirleri ortayaya dizip onlarla elbiselerini değiştirmiş ve bu fakirlerin çok sevindiğini ifade etmiştir.

Başka bir gün “...Hürriyet Tepesi’ndeki Talat Paşa’nın kabrinin gölgesine sı̆̆ııır. Niyeti üç dört günlük uykusunu atmaktır. Bir süre sonra bir hırpani etrafinda dönüp durmaya başlar. Belli ki niyeti kötü. Gözlerini sıkıca kapar adam yanına çöküp ceplerini karıştırmaya başlar.

-Utandim adamdan diyor.

Turkish Studies - History, 15(2) 
Neyzen bu, cebinde ne olacak, bir başpare(neyin üflendiği ăgızlık), birkaç kağıt parçasl, biraz bozukluk para. Hirsızın kismeti yok. Üzerine örttüğ̈̈ ceketin de yarlsı koca gövdesinin altında kalmış. Hırsız çekiyor ama kurtaramıyor. Ter içinde kalmış adamcağız. İşte burada artistliğini döktürmüş. Neyzen, inleyip horlayarak olduğu yerde bir dönmüş ceket kurtulmuş.

-Köftehor ceketi koltuğunun altına sıkıştırmış, tazı gibi kaçıyordu. Herhalde bir eskiciye satıp o akşamki nafakasını çıkaracaktı diye anlatıyor. Neyzen'de bir keyif bir keyif..." (Baştunç, 1991:68,69)

Bir süre Mısır'da yaşayan Tevfik, memlekete döndüğünde kendisinin bir konser vermesini istemişler ve bunun karşıllında 500 lira ödemişlerdir. Neyzen bu 500 lirayı köpeklerle halka dağıtmıştır. Bu olayla ilgili olarak Pendik Belediye başkanı Neyzen'in kardeşi Şefik Kolaylı'ya telefon açıyor:

-Aman Şefik Bey, aman buraya gel...Neyzen köpeklerin boyunlarına para bağlayıp salıveriyor. Halk köpekleri yakalamak için ardından koştukça hayvanlar daha fazla ürküyorlar. Pendik'te İskele başında ne kadar köpek varsa boyunlarına kağıt para bağllyarak salıveriyor.

Şefik Bey Neyzen'in yanına geldiğinde:

-Paraya ihtiyacı olanlara bir kısmını köpeklerle dağıttım diyor ve gülerek konuşmasına devam ediyordu:

-Şefik, görmeliydin, köpeklerin arkasından koşanlara ne kadar acıdım bilsen...Zavallı beşeriyet..." (Karaalioğlu, 2004:76).

İstanbul'da zenginlerin evlerini kendisine ardına kadar açtıkları halde Neyzen, bunları reddetmiş, yine dişarıda yatmıştır (Çapanoğlu, 1942:22). Hayri Yenigün Neyzen'in bu yönüyle ilgili bir anısında Neyzen'in nerede yattığını meyhaneciye sorduğunu ve Hocapaşa Camiinde bir tabutun içinde yattığı cevabını aldığını söylemiştir (Yücebaş, 1955:268).

Şiirde Millî Edebiyat Akımı içerisinde yer alan Neyzen Tevfik (Tural, Ocak 1993:135) Cumhuriyet dönemi hiciv ustaları arasındaydı (Öngören, 1983:157). Eleştirmedik hiçbir şeyi bırakmayan (Kara Mizah Antolojisi, 1987:125) Neyzen, yapılan toplantılara devamlı davet edilmiş, buralarda yaptığı hicivlerden kimse alınmamıştır (Belli, 12 Haziran 1963:sy). Bilakis bu durumdan memnuniyet duymuşlardır (Ergün, Eylül 1983:27). Neyzen'in hicvettikleri arasında en sevdiği kişilerden biri olan Mehmet Akif bile vardı (Hakkı Süha, 29 Birincikânun 1939:5). Mehmet Ergün, Neyzen'in hicivlerine kimsenin alınmamasının, bilakis bundan memnuniyet duymalarının nedenini bu kişilerin kendisini ciddiye almamalarının olduğunu söylemiştir (Ergün, Eylül 1983:26). Hastanede yatarken bir gün çevresindekilere söylenirken yanındaki Hüseyin Şehsuvaroğlu ile konuşurken O'na bu durumu sormuş, kendisinin önüne gelene birçok şey söylediğini ancak kendisine bir şey yapmadıklarını belirtmiş ve kendisinin ciddiye alınıp alınmadığını sormuştur (Şehsuvar, 2 Mayıs 1953:36).

Neyi ceketinin koltuk altında taşırdı. Bir ara ney yerine alüminyumdan bir boru taşımaya başlamıştı. Ney gibi yedi deliği olan bu borudan sesler çıkarmaya çalışıyordu. Ne yaptığını soranlara da; "bu soğuk boruya can vermeye çalışlyorum. Bakalım ney gibi adam olabilecek mi?" demişti (Baştunç, 1991:28). Her türlü kısıtlamaya karş1 olan Neyzen, bir ney taksimi sonrasında şöyle demiştir: "Ney kamıştan olacakmış! Bilmem kaç boğum olacakmış. Öyle mi? Böyle iddia edenler, (ney)in söylediğini zannederler. Söyleyen ney değil, onu söyletendir." Cevdet Ulunay, Neyzen'in boş bira şişesiyle bile ney çaldığına şahit olduğunu söylemiştir.

Neyzen Tevfik, Kanuni döneminde Çengi Benli Hanife'nin söyleyip oynadığg türküyü çok severdi. Neyzen'in dilinden düşürmediği bu türkü şöyleydi (Yücebaş, 1973:166-203): 
El sefâsın, ben cefâsın çekeyim
Çeke çeke içim bağrım kan oldu
Aramızda yemin oldu, andoldu.

Neyzen Tevfik giyime önem vermezdi. Münir Süleyman Çapanoğlu onun bu yönünü şöyle anlatmıştır: "Neyzen kllığına, klyafetine hiç dikkat etmezdi. Üstü başı meze lekelerile dolu, pis bir klyafetle gezerdi. Bir gün, kendisine bir elbise almak istedi, beraber gittik, bir hayli dolaştık, fakat bir şey almadı. Nihayet Balıkazarında bir meyhaneye girdik. Eskiden orada bazı meyhaneler vardı. Bunlar üst odalarında elbiseler, gemici eşyaları satarlardı. Bazıları da, gündüzleri basmacı, elbiseci dükkânıydl. Akşamları da meyhane...İşte bunlardan birinden mavi bir gemici tulumu aldl, günlerce böyle gezdi.

Mamafih raklyı bırakıp, boğazına düştüğ̈̈ zaman, derebeylikten vazgeçer, temiz bir insan olur. Birkaç yıl evvel raklyı bıraktı, midesine düştü. Bir mahallede oturduğumuz için, her gün görüyor, evine gidiyordum. Üstünde, başında lekeden çamurdan eser yoktu. Kolları, pantolonu meze lekelerile dolu değildi. Odası, en titiz bir kadının odasından daha derli toplu, daha pâk idi. Ve bir saray aşçısı ustalığı ile yemeklerini pişiriyor ve çamaşırlarını gıcırgıcır yılklyordu.

Maalesef bu uzun sürmedi..." (Çapanoğlu, 1942:33,34).

Neyzen Tevfik hayvanları çok severdi. Evinde sarı adında bir kedisi vardı (Bilginer, Ekim 1982:88). Mısır'da iken çakar almaz adını verdiği bir köpeği sahiplenmiş, İzmir'e getirdiğinde Mevlevihane'ye teslim etmişti (Yücebaş, 1973:73-77). Milli Mücadele döneminde Kara arslan adını verdiği ve boynuna zincir bağlayıp yanında gezdirdiği bir köpeği de vardı (Eşref Edib, 1938:230,231). Evinde kendi kedisinin dışında mahalledeki kediler de yaşamaktaydı. Yaşadığı yer ile ilgili olarak; "Burası kedilerin kervansarayıdır" demekteydi (Çapanoğlu, 1942:52,53). Muhittin Kutbay Tevfik'in hayvan sevgisiyle ilgili anılarını şöyle anlatmıştır: "Üstadın hayvanlara karşı derin bir merhameti, kedi ve köpeklere ise büyük bir zaafi vardl. Akll hastanesindeki odasina ikinci gidişimde onu tekir bir kedi ile oynarken bulmuştum. Bana takdim etmesi de hayli garipti:

-Bunu gördün mü? dedi. Ben buradan son defa ayrllırken anası gebe idi. Doğurduğunu göremeden taburcu oldum. Bu sefer odama yerleşir yerleşmez tekiri aradım. Biçare ben yokken kalıbı dinlendirmiş. Bunu da bana yadigâr bırakmış.

Tekir kedi, sanki Neyzen'in anlattıklarını anlıyormuş gibi başını çenesinin altında gezdirerek üstadı âdeta okşuyordu. Onun da eli kedinin sırtını sıvazlıyor ve Neyzen sustukça odanın içini memnunluk ifade eden kedi mırıltısı kapllyordu. Bazı kereler odasına girdiğim zaman Neyzen'i tekirle burun buruna uyurken bulur ve bu manzara karşısında uyandırmaya klyamayarak karşılarında ses çıkarmadan otururdum. Bana derdi ki: Hayvan seven insanlar merhametli, iyi kalplidirler. Benim bu notuma sen de mim koy."

Neyzen sonraları Mernuş isimli bir köpek sahiplenmişti. Her yere bununla beraber giderdi. Bu köpeği o kadar çok sevmişti ki, köpek ölünce köpeğini anlatan bir şiir kaleme almıştı. Köpeği mernuş için bir cenaze töreni de yapmıştı. Muhittin Kutbay bu cenaze töreniyle ilgili anılarında Neyzen'in insanlara yardım ettiğini çok gördüğünü, merhametli biri olduğu için hayvanları da çok sevdiğini, köpeği öldüğünde ç̧ok ağladığını, akıl hastenesindekilerle beraber köpeğini gömdüğünü anlatmıştır (Yücebaş, 1973:56-58).

Neyzen'in devamlı uğradığı yerlerden biri de Şehzadebaşı Eczanesi idi. Savaş döneminde İstanbul'da uyuz hastalağı yaygın idi. Neyzen'in çevresindeki insanlar da bu rahatsızlığı taşıyorlardı. Bundan dolayı kendisi de bu hastalıktan muzdaripti. Hastalık ortaya çıkınca eczaneye uğrardı ve "Dermoliv" adı verilen ilacı alırdı. Bu dükkan Neyzen içkisiz geldiğinde edebiyat 
tartışmaların yapıldığı, müzik eserlerinin icra edildiği bir yer haline geliyordu. Fatih Musiki Heyeti adında bir müzik topluluğu burada çalışırdı.

Neyzen s1k s1k eczacı hakkı beyin evini ziyaret ederdi. 1950'li yıllarda bir gün karın bir adam boyu olduğu, milletin kapılara ulaşmak için tünel kazdığı günlerden birinde yine Hakkı Bey'in evine uğramıştı. O gün evde bulunan Yüksel Baştunç bu ziyareti şöyle anlatmıştı: “...Postalının ipleri dolanmış. Durmadan küfür edip duruyor. Kafasında acayip bir şey var. Kirden meşin gibi olmuş bir kukuleta. Ikki yandan sarkan tutamakları bile var. Annem gelir gelmez feryadı bastyor:

-At şunu kafandan.

-Atamam hatırası büyük.

-Çıkar çıkar. Ben sana bir başlık örerim. Sıcacık tutar.

-Olmaz atamam. Milyonlarl verseniz atamam.

Sobanın başında ıslak çoraplarını kurutmaya çalışırken anlatıyor:

-Hemşire, o kaldır at dediğin şey, bana anacığımdan kalan tek hatıradır. Bana kalan tek mirastır. Malım mülküm hepsi odur.

-Soğuk havalarda öyle sicak tutuyor ki diyor" (Baştunç, 1991:10-33).

Sonuç olarak; büyük bir hiciv ve ney ustası olan Neyzen Tevfik, çocukken hastalığının ortaya çıkmasından sonra ailesi tarafından serbest büyütülmüştür. Bu süreçte Bodrum'da ney çalmaya başlayan Neyzen, Mehmet Akif'le tanıştıktan sonra şiirler yazmaya başlamıştır. Akif'in yanısıra şair Eşref'in de etkisinde şiirler yazmıştır. Daha çok neyiyle ün kazanmış, sonrasında ülkenin aranılan bir sanatçısı haline gelmiştir. Bir çok şiirinin yanısıra besteleri de bulunan Tevfik, hiciv alanında da ilerlemiş ve herkesi hicvetmiştir. Buna rağmen kimse O'na kızmamış, daha çok O'nun kendilerini hicvetmesinden memnun olmuşlardır. O'nun sanatçı kişiliği nedeniyle rahat bir yaşam sürmesi için uğraşmışlar, fakat Neyzen Tevfik, mizacı itibariyle bunları elinin tersiyle itmiştir. Yaşamı boyunca kendisine evler, maaşlar tahsis edilmesine, yedirilip içirilip giydirilmesine rağmen, $\mathrm{O}$ bu rahat hayata bir türlü alışamamış ve tekrar sokaklara dönmüş, sokaklarda yatmıştır. Neyzen bu hayatı süresince birçok ilginç olayla ve kişiyle karşılaşmış, bu olayların birçoğunda da kendisi yer almıştır. Bu süreçte yaşadığı bu ilginç olaylar halk arasında yayılmış ve halkın kendisine olan sevgisi daha da artmıştır. Neyzenliğinin yanısıra, nükteleri ile de Türk milletinin gönlünde unutulmayacak bir yer edinmiştir.

\section{Kaynakça}

Alpman, H.K. (1972). "Neyzen Tevfik”, Portreler, Sile Matbaa ve Mukavva Kutu Fabrikası.

Baştunç, Y. (1991). Ney’i Mey’i Sohbeti ile Neyzen Tevfik Uçtaki Adam, Yılmaz Yayınları A.Ş., Kuşak Ofset Matbaası.

BELLi, Ş. (1963) “Neyzen Tevfik’i Anarken”, Yelpaze, , sy.

Berk, N., Koloğlu O.(1971). Fikret Mualla(Hayatı-Sanatı-Eserleri), Milliyet Yayınları.

Bilginer, R. (1982). "Neyzen Tevfik”, Yazko Edebiyat, 83-88.

Çapanoğlu, M.S. (1942). Neyzen Tevfik, Hayatı ve Eserleri, Çı̆̆ır Kitabevi.

Dino, A., Güler A. Fikret Mualla, Cem Yayınevi, ty.

Engin, N. (1982). “Ölüm Y1ldönümünde Neyzen Tevfik (1879-1952)”, Eflatun, 14(157-158), 5-7. 
Ergün, M. (1983). Neyzen Tevfik ve Azâb-ı Mukaddes'i, Tunca Yayınları, Güryay Matbaacılık.

Ergün, M. (Eylül 1983). “Neyzen Tevfik ya da Söz’ün Özgül Ağırlı̆̆ı”, Bilim ve Sanat, (33), 26-32.

Ersoy, M.A. (1999). Safahat, Hazırlayan: M.Ertuğrul Düzdağ, Çağrı Yayınları, Enes Matbaacılık.

FirdevsiîTûsiGandhi Neyzen Tevfik Ahmet Cevdet Paşa, (1959). Hazırlayanlar: Ferit Ragıp TUNCOR, Salâhattin ARIKAN, Öğretmen Dergisi Gençlik Yayınları, İstiklâl Matbaası.

Hakkı Süha.(1939). “Neyzen Tevfik”, Yeni Местиa, 1-2(35), 5-20.

İnce, Y. (2007). “Alemleri Gezdi Hiç'in Peşinde-Neyzen Tevfik”, K Dergisi, Şan Ofset Matbaacılık San.ve Tic.Ltd.Şti., 2-5.

Kabacalı, A. (2003). Çeşitli Yönleriyle Neyzen Tevfik (Hayatı, Kişiliği, Siirleri), Özgür Yayınları: 41.

Kara Mizah Antolojisi, (1987). Hazırlayan: Enis Batur, Hil Yayın.

Karaalioğlu, S.K. (1983). Ansiklopedik Edebiyat Sözlüğü, İnkılâp ve Aka Kitabevleri, Yelken Matbaasi.

Karaalioğlu, S.K. (2004). Neyzen Tevfik (Hayatı ve Şiirleri), İnkılâp Kitabevi Yayın Sanayi ve Ticaret A.Ş. yayınları, Anka Basım.

Mutluay, R.(1973). 50 Yllın Türk Edebiyatı, Türkiye İş Bankası Kültür Yayınları: 126.

Münir Süleyman. (1953). “Neyzen Tevfik Beyi Dinlerken”, Yedigün, 1-2(27), 3-5.

"Neyzen Tevfik'in Son Seneleri ve Son Hatıraları...". (1953). Hafta, 8(177), 8.

Öngören, F. (1983). Cumhuriyet Dönemi Türk Mizahı ve Hicvi (1923-1983), Türkiye İş Bankas1 Kültür Yayınları, Yonca Matbaası.

Özata, M. (1977). “Neyzen Tevfik Üzerine”, Hisar, 17(165), 30-31.

Şehsuvar, H. (1953). “Büyük Neyzen'den Küçük Hatıralar”, Yeni İnci, 17(38).

Tarı, G. (1973). "Ney, Mey ve Neyzen Tevfik”, Milliyet Sanat Dergisi, 17, 10-12.

Tural, S. (1993). Şahsiyetler ve Eserler, Ecdâd Yayınları: 9.

Usta, R.(1985). Neyzen Tevfik (Hayatı, Sanatı ve Eserleri), Kastaş Yayınları, Dizerkonca Matbaası.

Yaşar, S. (2010). "Neyzen Tevfik (Yaşamı, Kişiliği ve Eserleri)”, Turkish Studies, 5(3), 1946-1969. http://dx.doi.org/10.7827/TurkishStudies.1536

Yaşar, S. (2008). "Mehmet Akif ve Neyzen Tevfik", 1.Uluslararası Mehmet Akif Ersoy Sетровуити, s.721-730.

Yaşar, S. (2016). "Neyzen Tevfik ve Bodrum”, Asos Journal, The Journal of Academic Social Science, 4(38), 31-37. http://dx.doi.org/10.16992/ASOS.11869

Yücebaş, H. (1955). Hiciv Edebiyatı Antolojisi, Dizerkonca Matbaası.

Yücebaş, H. (1973). Neyzen Tevfik (Hayatı-Hatıralart-Şiirleri), Milliyet Dağıtım, Yaylacık Matbaas1. 